\title{
LINKING RETIREMENT AGE TO LIFE EXPECTANCY IN A BISMARCKIAN SYSTEM - THE CASE OF GERMANY
}

\section{Valentin Vogt* Jörg Althammer*}

* Katholische Universität Eichstätt-Ingolstadt

NIESR Discussion Paper No.465

Date: 5 October 2016 


\section{About the National Institute of Economic and Social Research}

The National Institute of Economic and Social Research is Britain's longest established independent research institute, founded in 1938. The vision of our founders was to carry out research to improve understanding of the economic and social forces that affect people's lives, and the ways in which policy can bring about change. Seventy-five years later, this remains central to NIESR's ethos. We continue to apply our expertise in both quantitative and qualitative methods and our understanding of economic and social issues to current debates and to influence policy. The Institute is independent of all party political interests.

National Institute of Economic and Social Research

2 Dean Trench St

London SW1P 3HE

T: +44 (0)20 72227665

E: enquiries@niesr.ac.uk

niesr.ac.uk

Registered charity no. 306083

This paper was first published in October 2016

(c) National Institute of Economic and Social Research 2016 


\section{Linking Retirement Age to Life Expectancy in a Bismarckian System - The Case of Germany}

Valentin Vogt and Jörg Althammer

\section{Abstract}

In times of decreasing mortality, one way to stabilise a PAYG pension system is to interrelate the retirement age to the anticipated average lifespan. This paper investigates two approaches for Germany: one is to keep the average retirement duration constant, the other to define a constant share of the total lifespan for the retirement period. Our simulation model uses a Leslie matrix population projection, a Solow-Swan growth model and a detailed calculation of the German pension insurance budget. Our results show quite a significant impact on the insurance level and a rather small effect on the contribution rate, which is characteristic of a Bismarckian system.

\section{Contact details}

Valentin.Vogt@ku.de (corresponding author) and Joerg.Althammer@ku.de 


\title{
Linking Retirement Age to Life Expectancy in a Bismarckian System - The Case of Germany
}

\author{
Valentin Vogt, Jörg Althammer
}

\section{Introduction}

The demographic change is a major challenge to pay-as-you-go pension systems. Its two main driving forces - a steady increase in life expectancy and a low birth rate - lead to a severe change of the population structure. In a pay-as-you-go pension system under a balanced budget constraint, an increasing old-age dependency ratio can be compensated by an increase in the contribution rate or a decrease in the insurance level. ${ }^{1}$ Previous reforms have tackled these issues in a rather discretionary fashion, ${ }^{2}$ which makes it hard to identify the social phenomena a particular program tries to address. The limited time horizon of discretionary reforms and their lack of transparency create risks that necessary further reforms might be halted by voters and politicians or continued in the wrong way. Also they have an inherent danger of responding too strongly or weakly to the underlying problem. Rule-based approaches, on the other hand, are designed to tackle a specific issue and supposed to stabilise a system for a longer time period, and they are deducible in a more logical way from the underlying demographic processes.

We will analyse one of the main problems of public pension systems that has stirred up the public debate in Europe: the increasing life expectancy and the necessity to lift retirement ages. As a Bismarckian system ${ }^{3}$ can be expected to react in a much more complex way to such a reform than a system with flat pensions, we will suggest two different rule-based reform options for the German statutory pension insurance. We compare them to the legislative status quo in their effects on the two main outcome variables, contribution rate and insurance level. For this, an aggregate-level macroeconomic approach based on a statistical population and labour market participation projection with a detailed calculation of the pension insurance budget is applied. We simulate the effects of such rule-based reform options for the first time with such a model for both outcome variables with a time horizon until the year 2060 under plausible assumptions regarding the labour market reactions. A brief summary of our results is that the rule-based reforms have a rather high impact on the insurance level, while the impact on the contribution rate is very low. We hereby acknowledge that our results may not translate to non-Bismarckian systems.

In the next section, we will outline the main features of Germany's public pension system. Then, a short overview of the existing literature regarding similar rule-based approaches and models is given. After that, the construction of the selected scenarios and the simulation model are explained. Finally, the results of the calculations are discussed before the conclusion is given.

1 'Insurance level' refers to the net relative pension level before taxes of a standard pensioner, i.e. a person with a full earnings history from age 20 until the retirement age with earnings of exactly the average income subject to contributions in each year.

2 'Discretionary' hereby describes a reform that is not systematically aligned to the development of an indicator variable based on a clear theoretical foundation, but rather aims to keep several outcome variables within predefined ranges for a certain (arbitrarily selected) time. This does not necessarily mean a 'muddlethrough approach' or an ad-hoc reform, as a discretionary reform like the last pension reform in Germany can also define an adjustment process for a whole decade anticipating a development rather early but in a rather arbitrary way with unclearly defined goals.

3 A Bismarckian pension system is characterised by its direct link between an individual's earnings history and pension payments, by its pay-as-you-go mechanism based on contributions instead of taxes, and by its construction as a social insurance. 


\section{Germany's public pension system}

The German statutory pension insurance is a pay-as-you-go insurance system which is mandatory for most employees except civil service officials and the self-employed. It is based on the principle of participatory equivalence, which means that there is a linear relation between individual contribution payments and pension claims. This relation is described through remuneration points and the current pension value. A remuneration point is defined as the individual's yearly income divided by the average yearly income (both the income subject to contributions, which is limited by an upper cap). The current pension value in a specific year defines the relation between a pensioner's sum of accumulated remuneration points and the individual monthly pension payment. The current pension value, and thus the pensions, are adjusted to the wage growth and the demographic situation on a yearly basis with the following projection formula as defined in $\S 68$ and $\S 255$ e of the German Social Code VI (SGB VI):

$$
C P V_{t}=C P V_{t-1} \cdot \frac{G W_{t-1}}{G W_{t-2}} \cdot \frac{100-A-C R_{t-1}}{100-A-C R_{t-2}} \cdot\left(\left(1-\frac{P C R_{t-1}}{P C R_{t-2}}\right) \cdot \alpha+1\right)
$$

Here, CPV denotes the current pension value in time period t. GW is the average gross wage, $A$ is a constant set to $0.04,{ }^{4}$ and $\mathrm{CR}$ denotes the contribution rate. The first quotient in the formula is called the "wage factor", and the second one is the "contribution rate factor". Thus, pensions increase with rising wages and declining contribution rates. PCR is a standardised ratio between pensioners and contributors and $\alpha$ is an adjustment factor, deliberately set to 0.25 . The term $\left(\left(1-\frac{P C R_{t-1}}{P C R_{t-2}}\right) \cdot \alpha+1\right)$ is called the "sustainability factor". It adjusts the current pension value with respect to a deterioration of the pensioners/contributors ratio that might be caused either by demography or by changes in unemployment.

The flexibility of the retirement age in Germany is limited, which means that a large majority of the insured persons actually retires at or close to the retirement age. Early and later retirement are possible within narrow limits.

German social policy intends to stabilise the insurance level at $43 \%$ and to keep the contribution rate below $22 \%$ of gross income. These targets have also been defined in the Social Code VI until 2030, but the arguments for their justification are also valid beyond this year. As Figure 1 shows, the targets could not be met until the year 2030 if no retirement age reform was conducted. ${ }^{5}$ And, as life expectancy continues to increase and fertility rates are constantly at a very low level, both objectives are missed by far in the long run under these circumstances.

4 This constant represents the share of income an average person is supposed to invest in a special private pension insurance model called 'Riester-Rente' and is defined in $\S 68$ SGB VI.

5 The values for insurance level and contribution rate depicted in Figure 1 are calculated with our simulation model described later in this paper and represent the scenario "Baseline", a situation without any retirement age adjustment, as described in the following section. 


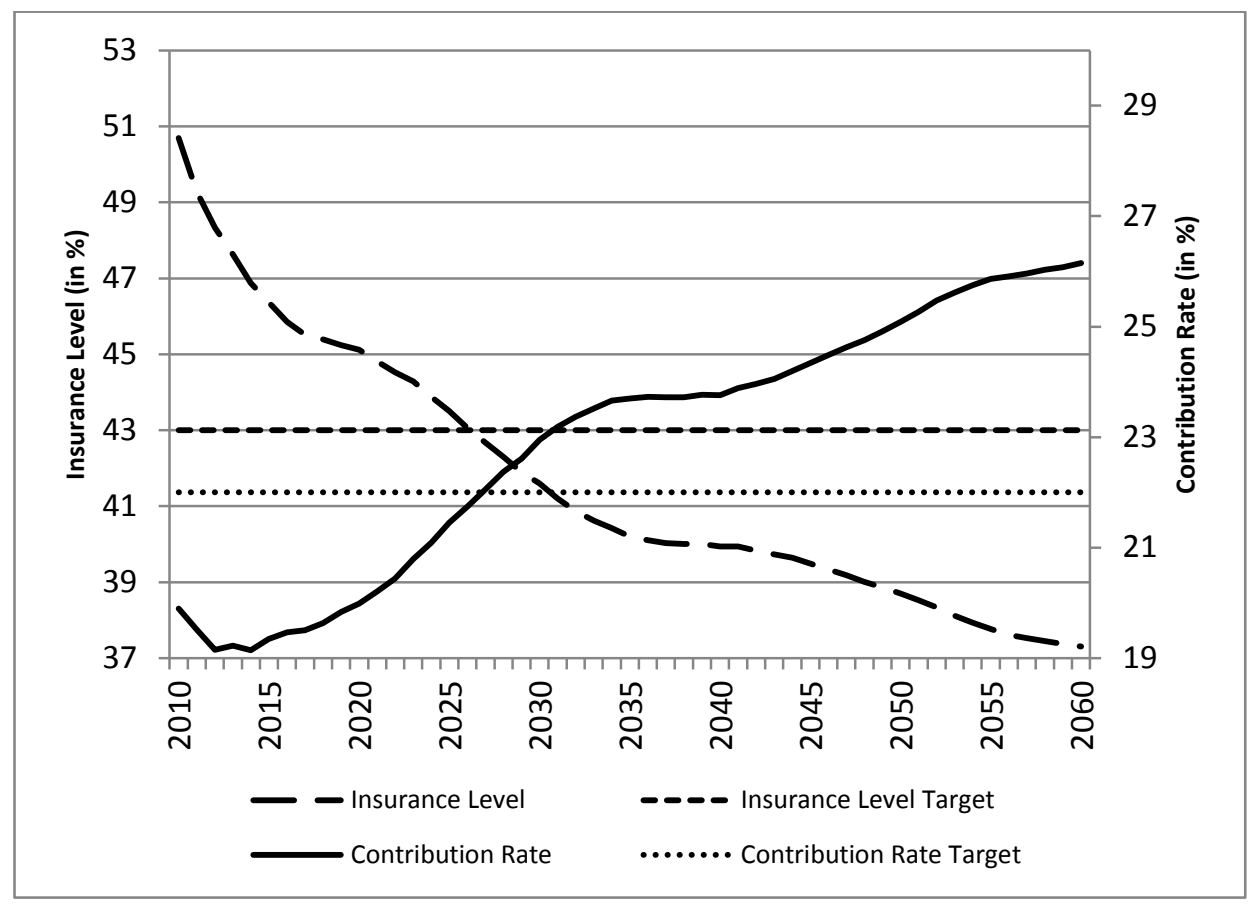

Figure 1: Contribution Rate and Insurance Level with a Constant Retirement Age of 65 (Source: own calculations)

Thus, in 2007 the German government has enacted a reform that raises the retirement age from 65 to 67 between the years 2012 and 2030. This act can be classified as a typical discretionary approach, as there is no link between the actual increase in life expectancy and the rise of the retirement age. Furthermore, this is a once-and-for-all raise of the retirement age that does not take into account that life expectancy will continue to rise after 2030.

\section{Literature overview}

As further increases in the retirement age seem inevitable, rule-based approaches that link the retirement age to life expectancy have been proposed by various authors. Schmähl and Viebrok (2000) compare a rule-based rise of the retirement age to other reform options such as general or cohort-specific decreases of the pension levels in an actuarial framework. They also point out that the effect of additional pension claims due to prolonged earnings histories in a Bismarckian system has a significant impact on pension levels and the general results of such a reform. Weizsäcker and Werding (2002) also suggest a rule-based approach for a link between retirement age and life expectancy. They use the CESifo pension model version of 2002 to simulate the long-term effects of this approach on the contribution rate and the implicit tax of the pension system. The simulated effects on the contribution rate seem quite strong. Gasche (2007) studies the intergenerational distributive effects of a rule-based rise of the retirement age within a theoretical framework. BörschSupan (2007) also suggests and theoretically examines such a rule-based rise of the retirement age among other reform options for a self-stabilising pension system in Germany.

While theoretical contributions on rule-based retirement age reforms can be found up to a reasonable extent, long-term simulation studies on this issue are rather scarce. Bucher-Koenen and Wilke (2008) use the MEA-PENSIM pension simulation model to investigate the long-term effects of the rise of the retirement age legislated in 2007 under several exogenously set employment behaviour scenarios. Besides the aforementioned contribution by Weizsäcker and Werding (2002), only the German Council of Economic Experts (2011) and Müller and Raffelhüschen (2011) analyse the long-term effects of a rule-based link between retirement age and life expectancy on the statutory pension insurance. In their report for 2011, the Council simulates the effects of a rulebased mechanism on the sustainability gap of public finances. Müller and Raffelhüschen (2011) 
analyse the effects of an introduction of a life expectancy factor into the pension formula on contribution rate and insurance level in comparison to a rule-based rise of the retirement age. However, scenarios covering plausible assumptions on labour market reactions are only taken into account for the life expectancy factor, while the retirement age rise is only simulated under the assumption of no labour market reaction at all. Thus, a study simulating the long-term effects of such rule-based retirement age rise mechanisms on the contribution rate and the insurance level with a time horizon beyond 2050 has not been conducted yet.

\section{Construction of the scenarios}

According to our demographic projections, we expect a further increase of average life expectancy from 85 years in the start year of our simulations, 2010, to 90 years in our terminal year, 2060, for women and from 82 to 88 for men. ${ }^{6}$ Thus, if no reform had been conducted and the retirement age stayed constantly at 65 , the expected retirement duration would increase from 20 years to 25 years. Even after the 2007 reform, the expected average retirement duration would increase from now 20 years up to 23 years by then. The scenarios analysed in this paper represent two of the most obvious possibilities for a link between retirement age and life expectancy.

The first scenario, "Constant Duration", aligns all of the gained additional years towards the work period and thus keeps the expected duration of the retirement period constant for each cohort. In other words, the retirement age is raised by one year for each year of life expectancy gain. This represents a quite radical approach, as it implies that people have to work for a longer time to reach the same expected duration of retirement as their predecessors, while they might not necessarily reach the same individual pension level due to the reduction of the insurance level.

The second scenario, "Constant Share", defines a more modest approach. At the same time, it is based on a slightly more complex rule. It defines a compromise, aligning parts of the gained years to both the work and the retirement period. The alignment ratio for each additional year is the same as the ratio between the expected retirement period and the rest of the life span (i.e. the work period plus the years from birth until the entry into the labour market). This means that the ratio between the retirement period and the rest of the life span is kept constant:

$$
\frac{\text { retirement duration }}{\text { education duration }+ \text { work } \text { period duration }}=\text { const } \text {. }
$$

In this case, every cohort is allotted the same amount of expected retirement duration per year of work/education period as the previous cohort. ${ }^{7}$

Both scenarios are constructed upon the differences in life expectancy with respect to the year 2011. This year was selected because it is the last year before the rise of the retirement age set by the current legislation begins. ${ }^{8}$

6 Both values represent the total life expectancy of a person aged 65 in the respective year. The method of projection is explained in the forthcoming paragraph 'Population Projection Module'.

7 One could argue that it does not seem obvious to summarize work and education to one period of life and that the alignment ratio should be the ratio between retirement and work period instead. But this does not take into account that parts of the education period also count for the accumulation of remuneration points in the German statutory pension insurance. The argument also ignores that the age of transition from education to the work period is set differently by each individual for good reasons, and the effects of this individual choice are reflected in the individual earnings histories and do not require an additional aggregate compensation by a rule-based retirement age setting.

8 The life expectancy differences are not measured as differences in the whole life expectancy, but as differences in the further life expectancy at the age of 65. This is exactly the expected retirement duration of

5 | Linking Retirement Age to Life Expectancy in a Bismarckian System - The Case of Germany 
The outcomes of both scenarios are compared to a scenario called "Reference 67". It represents the current status of legislation. The reform introduced in 2007 defines a gradual increase of the retirement age from 65 to 66 by one month for each yearly cohort between 2012 and 2024. After that, the increase is accelerated. The retirement age will further rise by two months per year, until it reaches 67 by the year 2031. This approach can be classified as discretionary for three reasons. First, the growth of the life expectancy does not show this discontinuity in its speed. Second, neither the slow nor the fast increase speed was set with a concept of alignment of the additional years to work and retirement period. They were set in order to meet the legal targets for contribution rate and insurance level until the year 2030. Third, up to now no further reaction to the supposedly continuing growth of the life expectancy after 2030 is defined by the law. Any further reaction would require a new political decision, which seems less likely than one could expect, as the current German government (and also most of the public debate) shows a clear tendency towards lowering the retirement age back to 65 for several groups rather than discussing a further increase. Thus, the "Reference 67" scenario modelled here does not contain any further increase of the retirement age after reaching 67 in 2031, unlike the other two scenarios. But, similar to them, "Reference 67" is constructed with steps by full years due to the restrictions of the pension insurance budget model.

To have a benchmark for the model specification and to show how the situation would look like without any retirement age rise, we also include a scenario called "Baseline". It represents a constant retirement age of 65 during the whole simulation period.

The two rule-based scenarios and the "Reference 67 " scenario lead to different amounts of increase steps and to a different timing of the steps, as Figure 2 shows. The discretionary nature of "Reference 67 " is shown by the fact that its increase speed grows, while the two rule-based scenarios slow down their increases with each step.

the cohort retiring in the base year, and this indicator contains the same amount of information as the life expectancy at birth as it is generated by the same projection using the same data. This projection of the further life expectancy at the age of 65 is taken from the population projection model described in the next chapter. The increases of the retirement age are modelled as a discrete function of the life expectancy with full years as the unit of the steps, because the applied pension insurance budget model can only align the date of entry into retirement to a certain year, not to a particular day or month. 


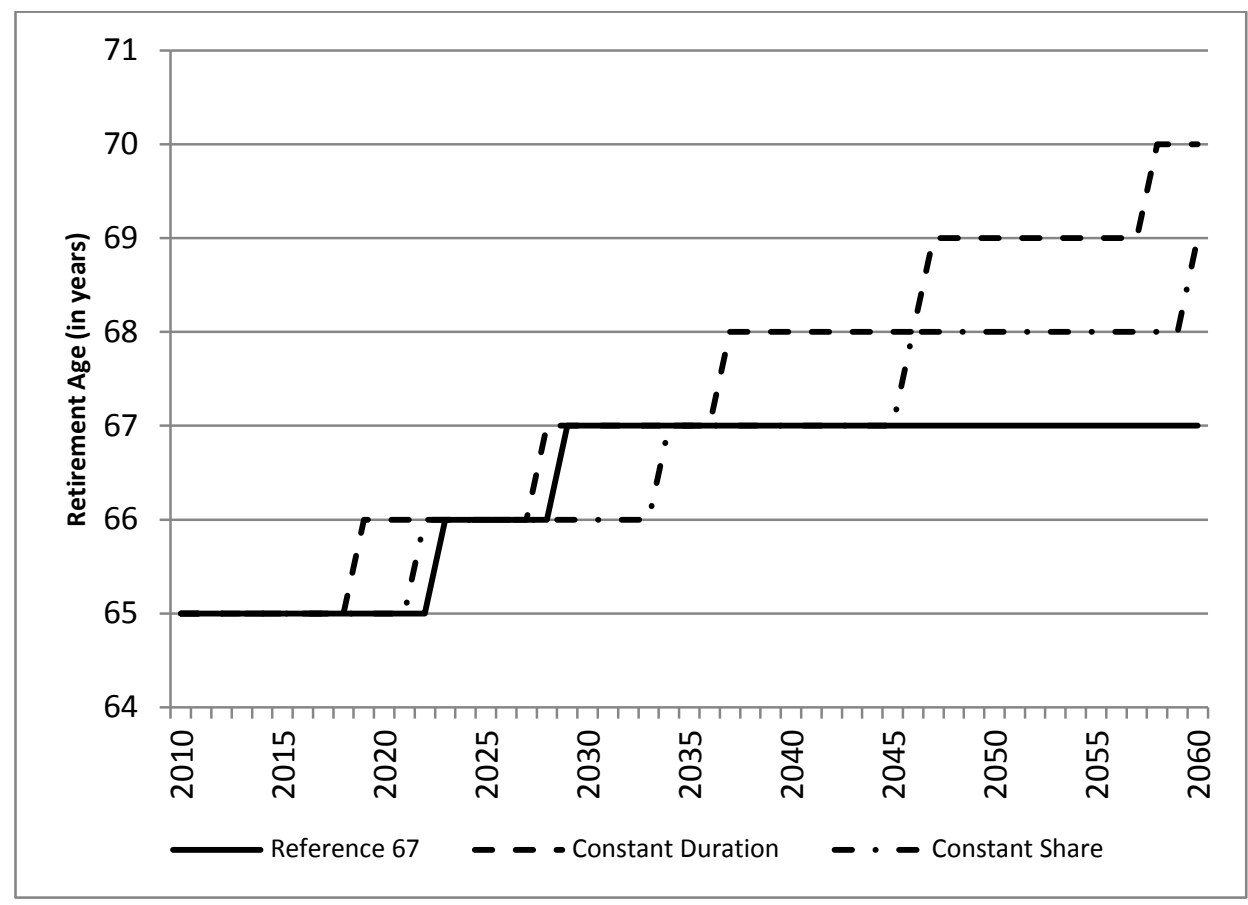

Figure 2: Retirement Age in the Different Scenarios (Source: own calculations)

\section{Demographic Macroeconomic Pension Simulation Model}

Our simulation model consists of four main parts: a population projection, a model of the labour market participation, a macroeconomic growth model and the projection of the budget of the German statutory pension insurance. We use a mainly deterministic partial-analytical framework on the aggregate level which is a common specification in macroeconomic long-term simulations of the German pension system (see i.e. Werding 2011 or Holthausen et al. 2012).

\section{Population projection module}

Demographic change is modelled as an exogenously induced process, as it is usually the case in official population forecasts by national statistical offices. The population projection module conducts a deterministic cohort-component projection based on the technique of Leslie matrices (see Caswell 2001). The domestic population is projected by age- and gender-specific survival and fertility rates.

The survival rates are assumed to change each year, so they are projected with the method of Bomsdorf and Trimborn (1992), a simplified version of the Lee-Carter method (see Babel et al. 2008). It is based on a regression of the logarithm of the mortality rates on time.

The fertilities are assumed to remain constant in each age, as projection methods detecting their trends are quite scarce. The total fertility rate is thus constantly held at 1.4. This is a common specification in demographic forecasting (see Holthausen et al 2012).

The migration flows of immigration and emigration are modelled with a parametric time series approach. First, the age structure of each stream (separated by gender) is parametrised by a Gompertz function similar to Castro and Rogers 1981. Second, the age structure for migration inflows and outflows is projected by an ARMA processes for the parameters of their Gompertz functions (see Vogt and Althammer 2015 for a method description and an analysis of the impacts of migration waves on the German pension insurance contribution rate). Finally, net migration is added to the domestic population. We hereby assume that the immigrants behave similarly to the domestic population on the labour market directly after their arrival in each specific age and gender 
group, and that emigrants disappear from the model after their emigration without any remaining pension claims. ${ }^{9}$

The initial data used for the population projection come from the current population statistics and the life tables of the Federal Statistical Office of Germany (Destatis). The main results are in line with the literature (i.e. Holthausen et al. 2012) and official population projections by Destatis. ${ }^{10}$

\section{Labour market participation module}

Labour market participation is modelled in two steps. Age- and gender-specific participation rates are projected using the statistical method of Burniaux et al. (2004). This method uses age-specific entry rates to and exit rates from the labour market to transform the participation rates age profile of one year to the next. The entry and exit rates are derived as age-specific averages from the participation rates published in the labour market data from Destatis for the years 2005 to 2011.

Entry and exit rates are projected by an algorithm similar to the one suggested by Burniaux et al. (2004) in order to adjust them to both the current trends of a later average entry into the labour market and also to the behavioural reactions to a rising retirement age. As the retirement age is not very flexible in Germany and the choices regarding individual retirement age decisions are very limited, the latter adjustment is merely conducted by synchronously shifting the exit rates of the age classes at or close to the retirement age to the age classes around the new retirement age. This means that the increase of the retirement age leads to an almost synchronous increase of the years in work, which is realistic unless a stronger flexibilisation is legislated alongside the reform. ${ }^{11}$

In the second step, the labour force is split into employed and unemployed persons. We assume the unemployment rate to be exogenous, as an endogenous unemployment rate would require an excessively complex general equilibrium model. It is defined as a scenario starting at the current value of $2010,7.7 \%$, and then linearly decreasing to $5 \%$ until 2020 . After 2020 , the unemployment rate remains constant at $5 \%$, which seems to be a plausible value according to several publications of the German Council of Economic Experts, i.e. Werding (2011).

\section{Macroeconomic growth module}

The economy is represented by a Solow-Swan growth model. ${ }^{12}$ We apply an aggregate-level CobbDouglas production function with two inputs, human and physical capital, which is augmented by a constant growth rate for the total factor productivity. The stock of human capital is given by

9 The first assumption, albeit unrealistic, is also used in similar models, i.e. Werding (2011) or Holthausen et al. (2012), as predictions on the integration process of immigrants for such a long time horizon cannot be made with enough certainty, and as only significant changes in the duration and outcomes of the individual integration processes would have an impact beyond time lags on the results. The second assumption can be made as the total amount of pension payments to emigrants by the German Statutory Pension Insurance is too small to require an explicit simulation for the simulation of a rise of the retirement age.

10 The life expectancy at birth reaches almost the same values as in the basis scenario of Destatis's $12^{\text {th }}$ coordinated population projection for Germany with 85.9 for male and 89.3 for female newborns. The total fertility rate of constantly 1.4 during the whole simulation is also used in their basis scenario. The net migration is also within the range of Destatis's scenarios, but not with a constant value, and with a peak during the first years of projection. After 2020, it is below the value of 200,000 of the upper limit scenario of Destatis. Then it slowly decreases to 165,000 in 2060, which is still closer to the upper limit than to the lower limit of Destatis, which lies at 100,000. A figure showing the net migration by year can be found in the online appendix. The population size decreases from 81.8 million to 71.2 million, while the old-age dependency ratio goes up from $31.2 \%$ to $62.1 \%$. These values are close to Destatis's basis scenario with the upper limit migration which seems appropriate considering the current development.

$11 \mathrm{~A}$ basic sensitivity analysis for the stability of our results under different labour market assumptions has been added to the online appendix.

12 We assume a closed economy, as in Werding and Hofmann (2008). 
projected aggregate labour supply, weighted by a quality index increasing with a constant rate. The capital stock is projected with a constant savings rate applied to average earnings and a constant depreciation ratio. The macroeconomic growth module is used to project the labour productivity and thus the average wages, and the gross domestic product. The data for the calibration of the growth model is taken from the Ifo Productivity Database as published in Werding and Hofmann (2008).

\section{Pension insurance budget module}

The core of the model is the detailed calculation of revenues and expenditures of the pension insurance. The calculations are divided into several steps similar to Holthausen et al. 2012.

First, each cohort's average earnings histories are tracked. A relative age profile of the wages subject to contributions is estimated from cross-sectional data of the German statutory pension insurance, and then kept constant over time, as it has been nearly constant in the past. The growth of the average gross wages and the average wages subject to contributions is assumed to be equal to the growth of labour productivity taken from the macroeconomic growth module. Then the average remuneration points a cohort acquires in each year are calculated from their earned wages. They are summed up and the remuneration points gained before the initial year are added. Different individual entries into retirement within cohorts are taken into account in the cohort average sums of remuneration points and deduction factors. The same holds for shorter earnings histories of immigrants. Differences in the remuneration point accumulation before the early retirement age between individuals retiring early and at the retirement age have to be ignored as income heterogeneity is only included regarding age, gender and cohort.

In the third step, the actual calculation of contribution and pension payments is carried out iteratively. First, the CPV is projected from one year to the following year as defined in the Social Code VI. Then, the pension payments for old-age, survivor's and reduced earnings capacity pensions and other benefit payments by the statutory pension insurance are calculated from the earnings histories from step two. On the revenue side, the government subsidies for the statutory pension insurance are projected first. After all other parts of the budget have been calculated, the contribution rate is set so that the contribution payments balance the budget.

In a last step, the insurance level is derived from the CPV, the contribution rate and the average gross wages for each year. The contribution rates of the other social insurances, which are necessary for this calculation, are assumed to be exogenous. Their path is set to the same values as published in Werding (2014).

\section{Results}

The first finding is that the effects of the rule-based approaches on the contribution rate are very small, as Figure 3 shows. Until 2035, the effects are almost insignificant, but the retirement age difference of both rule-based reforms to the "Reference 67" scenario also remains quite small until then. After 2035, the difference in the contribution rate becomes significant, but it remains smaller than 0.1 percentage points. Both scenarios reach approximately the same maximum difference, which indicates that the main effect is to be found elsewhere, especially when taking into account that the difference is slightly stronger in the more moderate "Constant Share" than in the "Constant Duration" scenario. 


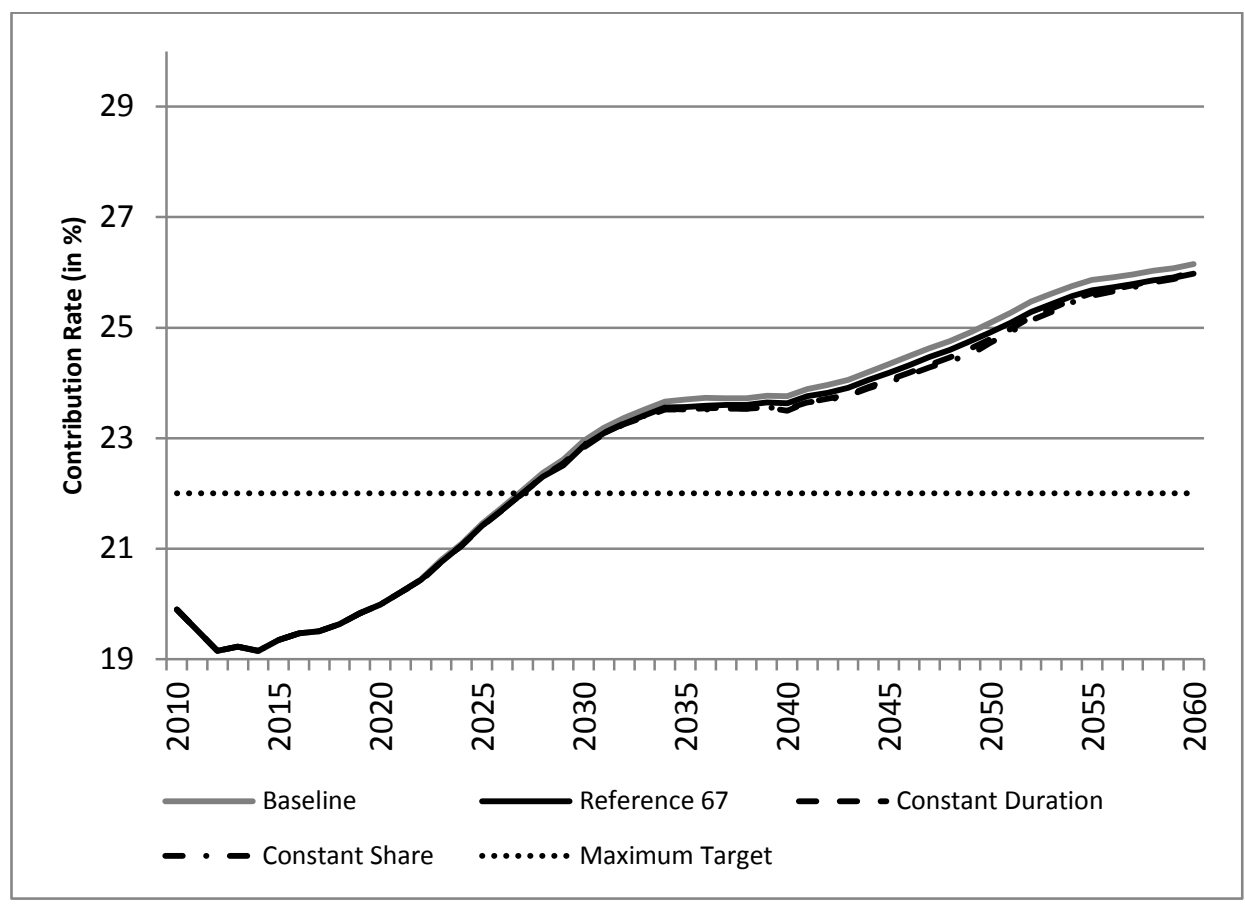

Figure 3: Contribution Rate in the Different Scenarios (Source: own calculations)

Figure 4 shows that the main effect of both scenarios is on the insurance level, with a maximum difference of more than two percentage points between "Reference 67" scenario and "Constant Duration", or almost two percentage points between "Reference 67" and "Constant Share". This is a huge effect compared to i.e. the effects of large migration waves (see Vogt and Althammer 2015) or even compared to a massive variation in the fertility (see Holthausen et al. 2012). In the medium term, the "Reference 67" scenario can offer an insurance level in the middle between the insurance levels of the two rule-based scenarios though, due to its discretionary higher speed of increase of the retirement age. Around 2035, the rule-based approaches reach much higher values than "Reference 67", as they continue with their rise of the retirement age, while the "Reference 67" scenario stops it here. For the first years after the retirement of the last baby boom cohorts, a slight increase of the insurance level can be observed in both scenarios. But after this small peak is reached around 2045, the level resumes its decrease again, albeit with a much slower pace than in the "Reference 67" scenario. As expected, the two rule-based scenarios have almost the same path in the first quarter of the simulated period, and after that the difference between them continuously grows, while they behave very similarly in all other respects. 


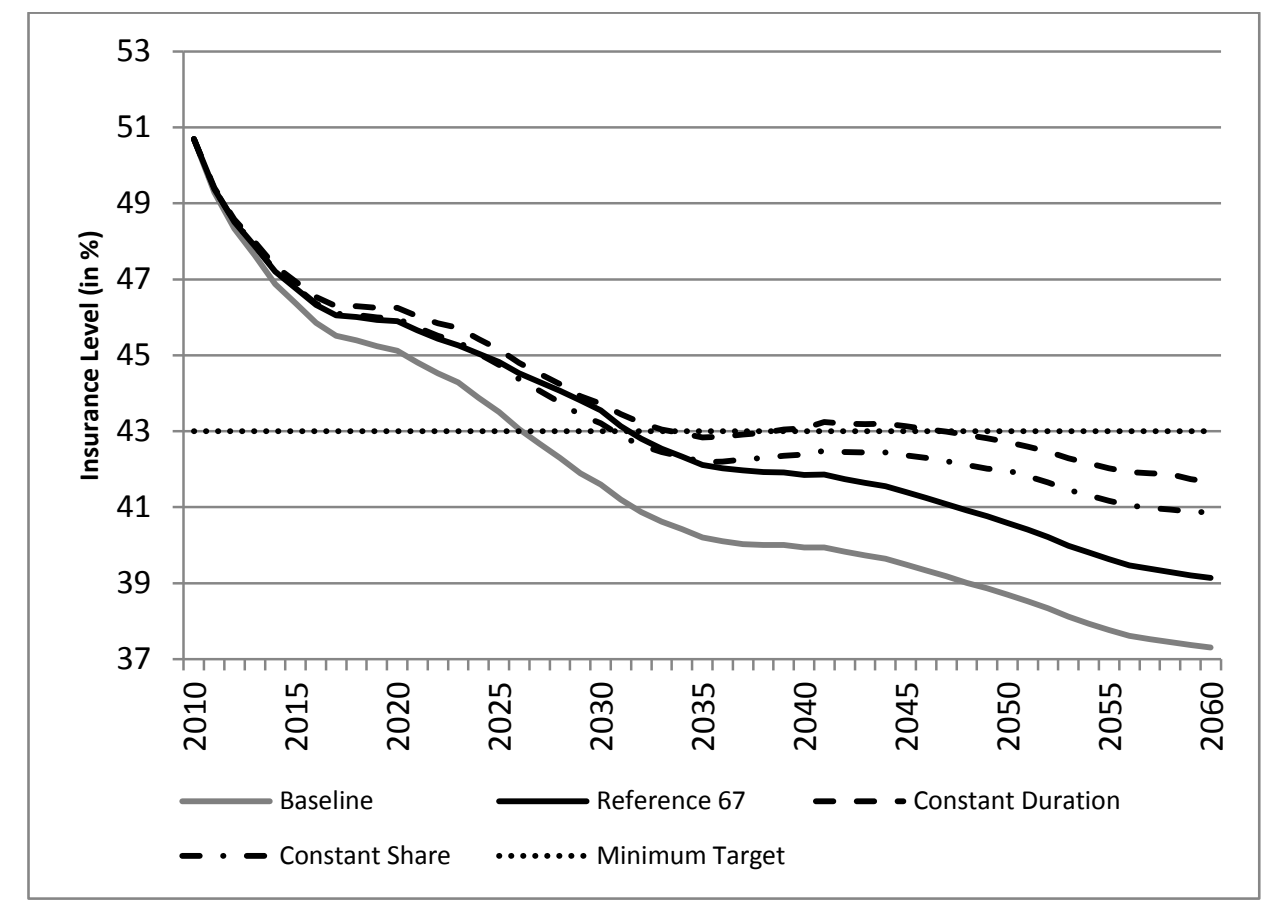

Figure 4: Insurance Level in the Different Scenarios (Source: own calculations)

Hence the two rule-based reforms cannot lower the contribution payment burden for the insured persons, while they can indeed increase the monthly pensions of the retired. The reasons behind this lie within the typical Bismarckian features of the German pension system. Unlike a typical Beveridgean system with its flat pension level, the actual amount of an individual's monthly pension is directly correlated to the contributions a pensioner has paid. Thus, each year of employment raises the monthly pensions, which is also the case for the additional one or two years caused by the further rise of the retirement age in our two scenarios. This almost cancels out the effect of a slightly lower number of pensioners on the total pension payments. Another explanation lies within the wage development in the closed economy growth model. The larger labour force results in lower wages, which moderate the development of the CPV directly through the wage factor and indirectly by cancelling out the effects on the sustainability factor in its projection formula. The lower wages also more than compensate the effect of the larger labour force on the tax base for contributions.

\section{Conclusion}

In this paper we have suggested two different rule-based approaches for a link between retirement age and life expectancy in Germany: a constant duration of the retirement period or a constant share of the average life duration reserved for the retirement period. Both approaches are more consistent than the discretionary approach currently set by legislation, which does not show a direct correlation between retirement age and life expectancy, and especially did not specify a reaction to the further increase of the life expectancy after 2030 yet.

Both rule-based approaches have a noteworthy impact on the insurance level in comparison with the "Reference 67" scenario based on the current legislation, mainly due to the accumulation of additional pension claims during the longer work period. On the other hand, the impact of both reform options on the contribution rate is almost insignificant. This is caused by several different effects cancelling each other out because of the wage development and especially due to the additional pension claims. The latter ones are a typical feature of a Bismarckian pension system with its direct correlation between the contribution histories and the monthly pensions for each individual, which means that the findings would be different in a flat Beveridgean pension system. 
Another finding is that the legally set targets for the contribution rate will be missed by far under all three scenarios soon after 2030. On the other hand, the "Constant Duration" scenario satisfies the target condition for the insurance level until 2050 and its insurance level remains very closely below the target until 2060. The "Constant Share" scenario performs less well here, but its insurance level also remains way above the "Reference 67" scenario. Hence both rule-based approaches can contribute to a more modest decrease of the insurance level, especially the "Constant Duration" scenario.

In general, both rule-based approaches, "Constant Duration" and "Constant Share", can significantly contribute to an improvement of the demographic sustainability of the German statutory pension insurance. But, as they only aim at mitigating the effects caused by a steadily increasing life expectancy, they cannot compensate for the impact of other demographic developments, especially the constantly low birth rates. For these developments, further reform proposals are needed in order to keep the German statutory pension insurance sustainable in the long run.

\section{Bibliography}

Babel, B., Bomsdorf, E. and Schmidt, R. (2008), 'Forecasting German mortality using panel data procedures', Journal of Population Economics, 21, pp. 541-555.

Bomsdorf, E. and Trimborn, M. (1992), 'Sterbetafel 2000 - Modellrechnungen der Sterbetafel', Zeitschrift für die gesamte Versicherungswirtschaft, 81, pp. 457-467.

Börsch-Supan, A. (2007), 'Rational Pension Reform', The Geneva Papers on Risk and Insurance Issues and Practice, 32, pp. 430-446.

Bucher-Koenen, T. and Wilke, C. B. (2008), 'Zur Anhebung der Altersgrenzen: Eine Simulation der langfristigen Auswirkungen auf die gesetzliche Rentenversicherung bei unterschiedlichem Renteneintrittsverhalten', MEA Discussion Paper 159-2008, pp. 1-36.

Burniaux, J., Duval, R. and Jaumotte, F. (2004), 'Coping with Ageing: A Dynamic Approach to Quantify the Impact of Alternative Policy Options on Future Labour Supply in OECD Countries', OECD Economics Department Working Papers 371, pp. 1-91.

Castro, L. and Rogers, A. (1981), Model Migration Schedules, IIASA RR-81-30, International Institute for Applied Systems Analysis.

Caswell, H. (2001), Matrix Population Models: Construction, Analysis and Interpretation, Sinauer Associates.

Gasche, M. (2007), 'Intergenerative Verteilungseffekte der (modifizierten) Schutzklausel und der Anhebung des gesetzlichen Renteneintrittsalters', Deutsche Rentenversicherung (DRV), Vol. 62, No. 2-3, pp. 159-169.

German Council of Economic Experts (2011), 'Herausforderungen des demografischen Wandels', Expertise im Auftrag der Bundesregierung.

Holthausen, A., Rausch, J., Wilke, C. (2012), 'MEA-PENSIM 2.0: Weiterentwicklung eines Rentensimulationsmodells, Konzeption und ausgewählte Anwendungen', MEA Discussion Papers 254-2012. 
Joebges, H., Meinhardt, V., Rietzler, K. and Zwiener, R. (2012), 'Auf dem Weg in die Altersarmut: Bilanz der Einführung der kapitalgedeckten Riester-Rente', IMK Report 73, Institut für Makroökonomie und Konjunkturforschung (Macroeconomic Policy Institute).

Müller, C. and Raffelhüschen, B. (2011), 'Demografischer Wandel: Künftige Handlungsoptionen für die deutsche Rentenpolitik', IZA Standpunkte, 40.

Schmähl, W. and Viebrok, H. (2000), 'Adjusting Pay-as-you-go Financed Pension Schemes to Increasing Life Expectancy', Schmollers Jahrbuch, 120, pp. 41-61.

Vogt, V. and Althammer, J. (2015), 'Zuwanderung nach Deutschland: Makroökonomische Szenarioanalyse der Auswirkungen verstärkter Migration auf Altenquotient und Beitragssatz zur gesetzlichen Rentenversicherung', DGD-Online-Publikation, 1/2015, pp. 38-49.

Weizsäcker, J. and Werding, M. (2002), 'Demographiefest: Rentenfinanzen und Lebenserwartung', ifo Schnelldienst, 55 (11), pp. 42-45.

Werding, M. and Hofmann, H. (2008), 'Projektionen zur langfristigen Tragfähigkeit der öffentlichen Finanzen', ifo Beiträge zur Wirtschaftsforschung 30/2008.

Werding, M. (2011), 'Demographie und öffentliche Haushalte: Simulationen zur langfristigen Tragfähigkeit der gesamtstaatlichen Finanzpolitik in Deutschland', Arbeitspapier 03/2011, German Council of Economic Experts.

Werding, M. (2014), 'Demographischer Wandel und öffentliche Finanzen: Langfrist-Projektionen 2014-2060 unter besonderer Berücksichtigung des Rentenpakets der Bundesregierung', Arbeitspapier 01/2014, German Council of Economic Experts.

\section{Appendix}

\section{Simulations with a fixed insurance level path}

In addition to our calculations with a normal projection of the current pension value, we also simulate the effects of our scenarios on the contribution rates under the assumption of a fixed insurance level path which does not fall below the minimum of $43 \%$. The reason is that it seems very unlikely that our rule-based approaches regarding the retirement age could also be able to stabilise the contribution rate and insurance level against the influences of all other demographic developments such as the steady low birth rates. We decided to simulate a fixed insurance level path because the threshold of $43 \%$ seems to be a necessary condition in order not to face severe old-age poverty problems and thus acceptance problems for the statutory pension insurance (see i.e. Joebges et al. 2012), while a violation of the contribution rate threshold of $22 \%$ seems to have less severe acceptance consequences. Hence the question here is how much our rule-based approaches can help to lower the contribution rate under these conditions, and how much more need for additional reforms there is.

For this simulation, a change in the calculation of the CPV is necessary. Instead of projecting it according to the Social Code VI, we iteratively calculate the CPV which is necessary to obtain the predefined insurance level in each year. The insurance level is hereby set to either its value in the normal "Reference 67 " scenario simulation in the respective year or $43 \%$ if the value falls below this threshold. The rest of the calculations is done in the same way as described above for each scenario. 
Under the constraint that the insurance level is defined to follow the path of the "Reference 67" scenario until it reaches the minimum of $43 \%$ and then stay at this minimum for the rest of the retirement period, the outcomes of the scenarios can be measured by just one variable, the contribution rate. Figure 5 shows the development of the contribution rate in the "Baseline" scenario, the "Reference 67" scenario, and in both rule-based reform scenarios under the fixed insurance level constraint.

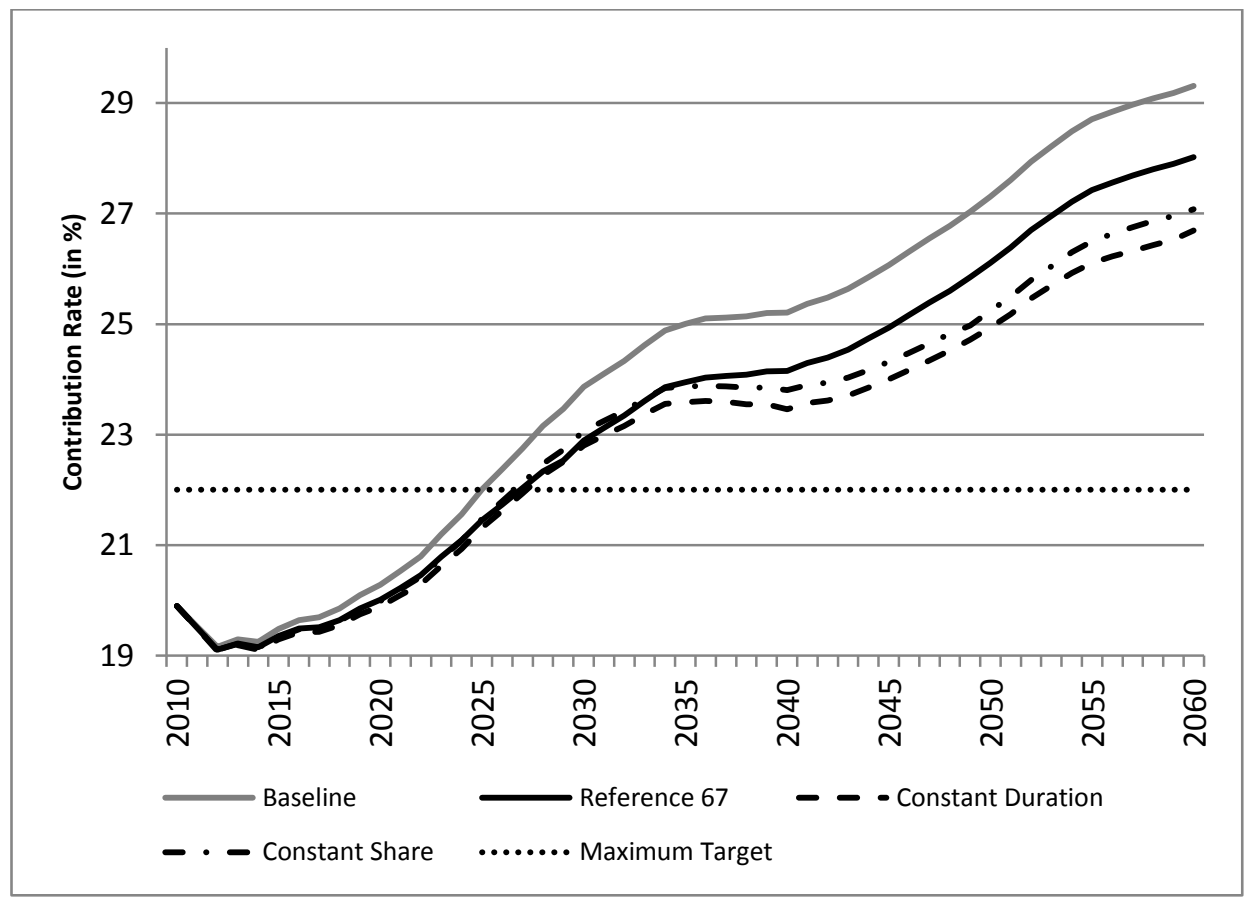

Figure 5: Contribution Rate in the Different Scenarios with a Fixed Insurance Level Path (Source: own calculations)

The rule-based approaches have rather big effects here. Their contribution rates reach a small peak in 2035 and then decrease slowly until 2040, where the hardly avoidable increase starts. But this increase is much more modest than in the "Reference 67" scenario, and much smaller values are reached by 2060. The difference compared to the "Reference 67" scenario grows up to almost a full percentage point in the "Constant Duration" scenario, while it still reaches almost half a percentage point in the "Constant Share" scenario. It is also noteworthy that the difference between both rulebased scenarios stays rather small, though this was expectable because of their rather moderate insurance level difference in the normal simulation and the almost insignificant contribution rate difference there.

\section{Conclusion of the simulations with a fixed insurance level path}

If no future scope for a decrease of the insurance level below the current threshold of $43 \%$ can be politically tolerated (i.e. due to rising old-age poverty problems), then the contribution rate has to carry the whole demographic burden. Our simulations with a fixed path for the insurance level constantly remaining at this threshold show that both rule-based reform approaches could significantly improve the development of the contribution rate in comparison with the current legislation regarding the retirement age, at best by almost a full percentage point. On the other hand, the contribution rate exceeds its target maximum by far and reaches unsustainable values in all three scenarios. 


\section{Brief sensitivity analysis regarding our labour market reaction assumptions}

In our labour market module we assume an almost full transmission of the rise of the retirement age to a rise of the actual years in work. As explained there, this is a quite realistic assumption as the flexibility of the retirement age is low in Germany. However, to analyse the sensitivity of our results against smaller reactions on the labour market, we have also conducted the otherwise exactly same simulations under the most radical assumption that is possible: the assumption that the labour market does not react at all, and that the actual entry into retirement takes place in the same age as without any change in the statutory retirement age. The results are shown in Figure 6 and Figure 7. A comparison to the respective figures within the paper (those representing a full labour market reaction) shows that there is almost no difference in both variables, so our result seem to be very stable against different labour market assumptions. The reason for this is that the various underlying effects cancel each other out in the projection of the current pension value, the numbers of pensioners and contributors and thus in the budget of the pension insurance. We hereby acknowledge that this is just a brief sensitivity analysis and further investigations on the influence of labour market assumptions might be helpful in the future.

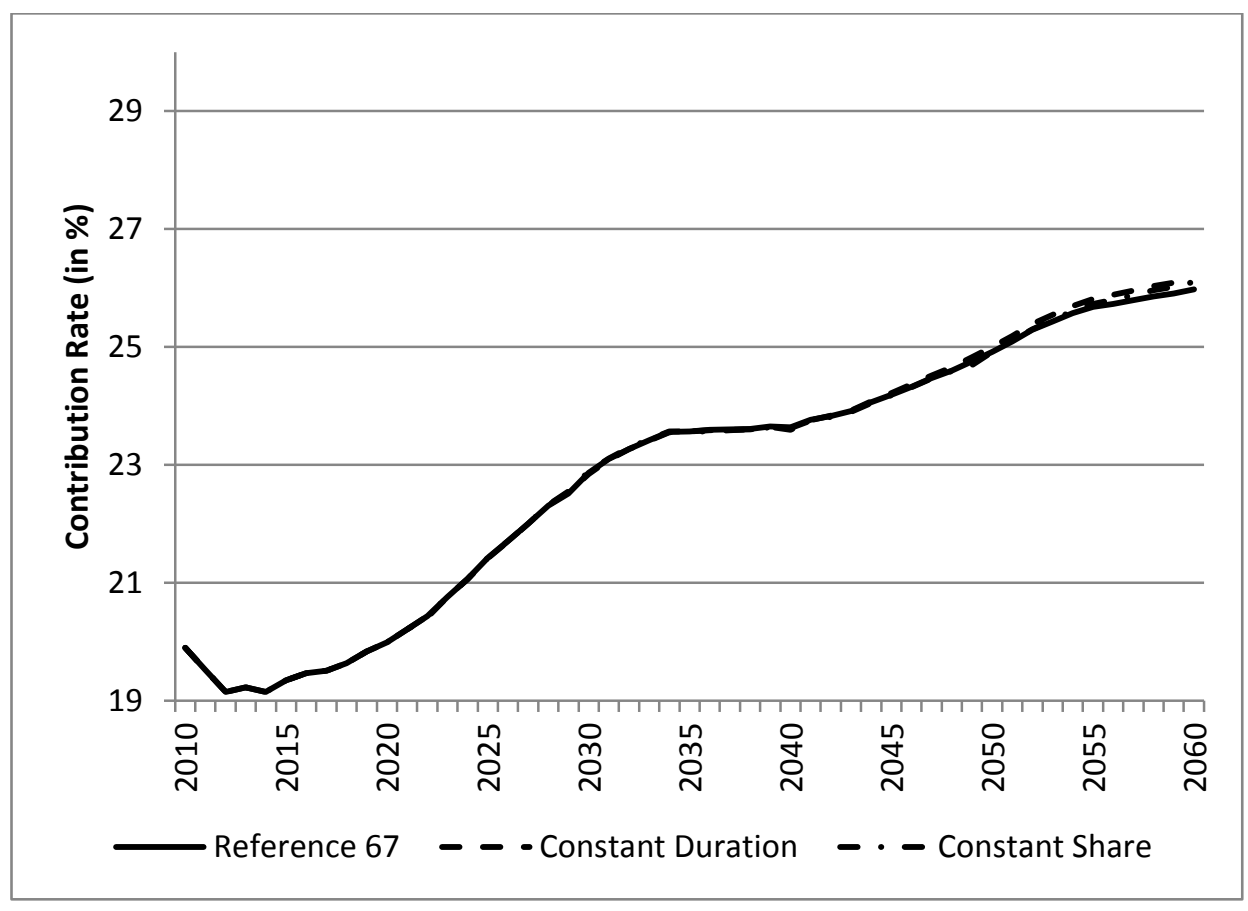

Figure 6: Contribution Rate under the Assumption of no Labour Market Reactions (Source: own calculations) 


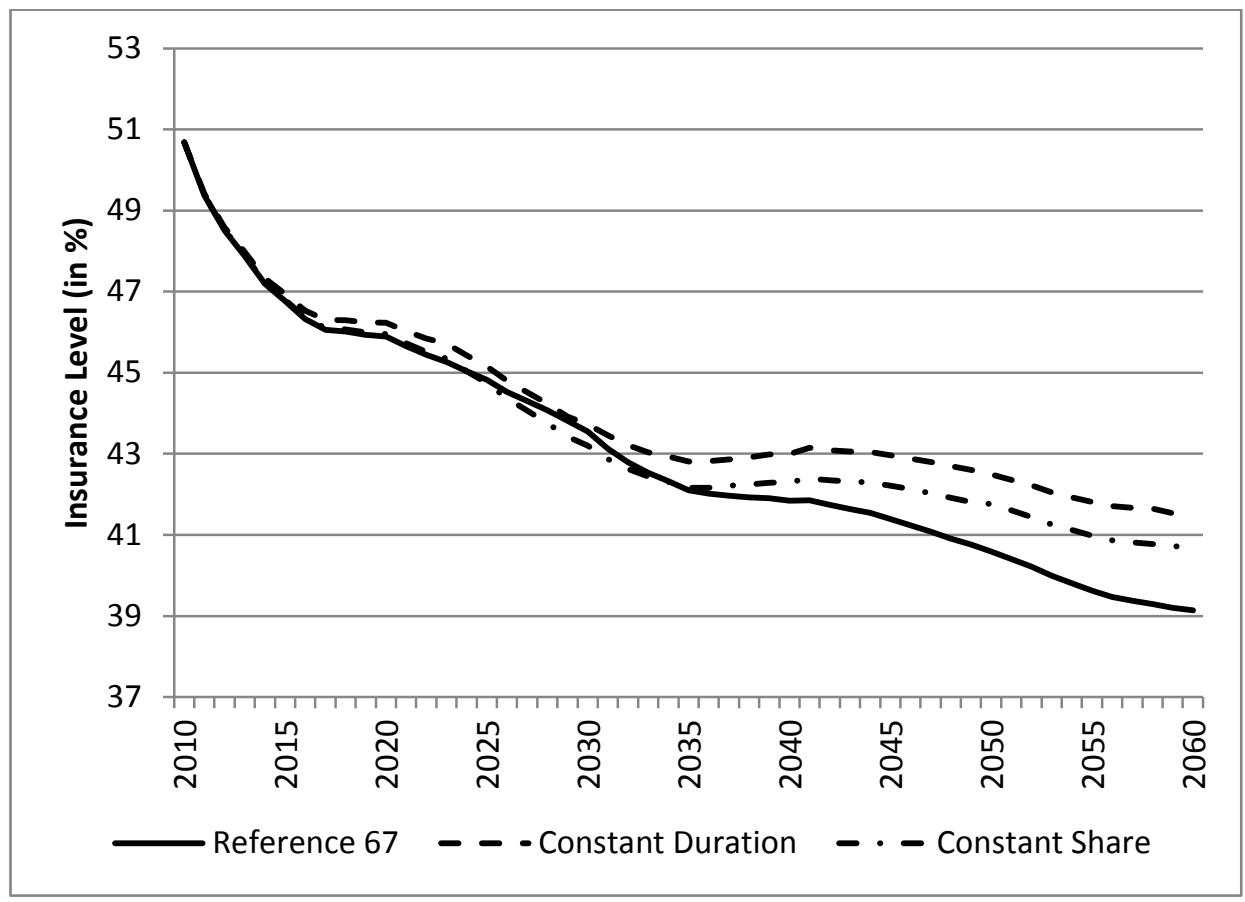

Figure 7: Insurance Level under the Assumption of no Labour Market Reactions (Source: own calculations)

\section{Net migration}

The net migration in each simulated year is depicted in Figure 8. The method of projection is described within the paper in the paragraph "Population Projection Module".

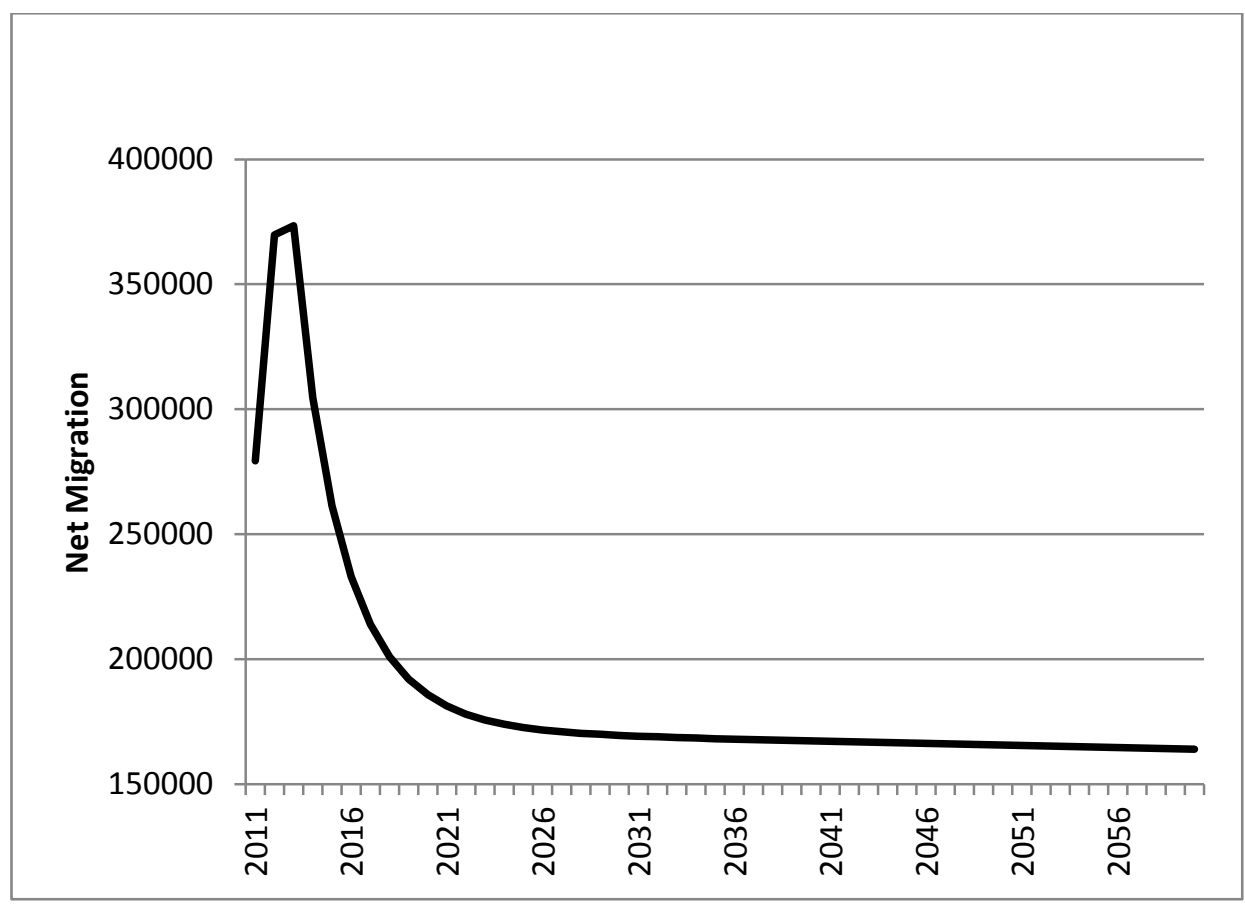

Figure 8: Net Migration (Source: own calculations) 